\title{
BMJ open Employment status and work-related problems of gastrointestinal cancer patients at diagnosis: a cross-sectional study
}

\author{
A G E M de Boer, ${ }^{1}$ D J Bruinvels, ${ }^{1} \mathrm{~K}$ M A J Tytgat, ${ }^{2,3}$ A Schoorlemmer, ${ }^{2,3}$ \\ J H G Klinkenbijl, ${ }^{3,4}$ M H W Frings-Dresen ${ }^{1}$
}

To cite: de Boer AGEM, Bruinvels DJ, Tytgat KMAJ, et al. Employment status and work-related problems of patients with gastrointestinal cancer at diagnosis: a cross-sectional study. BMJ Open 2011;2:e000190. doi:10.1136/bmjopen2011-000190

- Prepublication history for this paper is available online. To view these files please visit the journal online (http:// bmjopen.bmj.com/context/ early/recent).

Received 31 May 2011 Accepted 4 August 2011

This final article is available for use under the terms of the Creative Commons Attribution Non-Commercial 2.0 Licence; see http://bmjopen.bmj.com

For numbered affiliations see end of article.

Correspondence to Dr A G E M de Boer; a.g.deboer@amc.nl

\section{ABSTRACT}

Objective: To assess the employment status of patients with gastrointestinal cancer at diagnosis and to examine work-related problems of employed patients.

Design: New, consecutive patients were included at the Gastrointestinal Oncology Center Amsterdam, a one-stop, rapid access diagnostic assessment centre. Patients were interviewed on their employment status by a nurse. If (self-) employed, patients were asked to self-report on work-related problems, perceived distress $(0-10)$, cancer-related problems, fatigue (MFI-20, range 4-20) and work ability (three WAI questions, range $0-10$ ).

Results: Of all 333 included new consecutive patients (age range $32-89$ years), 95 patients $(28 \%)$ were (self-) employed at time of diagnosis, $179(54 \%)$ were pensioners, and 59 were not working (18\%). For the assessment of work-related problems, $45(47 \%)$ of these 95 employed patients with cancer participated. Their mean age was 56 years, and patients had oesophageal/stomach $(49 \%)$, colorectal $(18 \%)$ or hepatic/pancreatic/biliary cancer (33\%). Half of the employed patients (49\%) were still at work, while $51 \%$ were on sick leave. The main reasons for sick leave were stress (35\%), (scheduled) operation (26\%), fatigue $(17 \%)$ and pain (13\%). Most patients on sick leave $(70 \%)$ had no contact with their own occupational physician, although the majority (67\%) would like to continue to work. Work-related problems were experienced by $73 \%$ of working patients. The mean work ability was 5.4 , the mean general fatigue score was 11.5, and the mean distress score was 4.7. Employed patients on sick leave reported a lower work ability, more fatigue and higher distress but no more cancerrelated problems compared with those still working.

Conclusion: A quarter of all patients with gastrointestinal cancer seen at an oncological centre are employed at time of diagnosis, and of these employed patients, $73 \%$ experience work-related problems. During diagnosis and treatment, information and support on work-related issues should be offered to patients with cancer as an essential part of highquality oncological care.

\section{ARTICLE SUMMARY}

Article focus

- This article focuses on the employment status of patients with gastrointestinal cancer at time of diagnosis and examines employment status and work-related problems of employed patients with gastrointestinal cancer.

Key messages

- A quarter of all patients with gastrointestinal cancer seen at an oncological centre are employed at the time of diagnosis.

- Of these employed patients, $73 \%$ experience work-related problems.

- During diagnosis and treatment, information and support on work-related issues should be offered to cancer patients as an essential part of highquality oncological care.

Strengths and limitations of this study

- The strength of this study is the inclusion of all new, consecutive patients at time of diagnosis.

- The patients included received highly specialised oncological care provided by our medical centre, mainly focusing on secondary and tertiary referral. This might have limited the generalisibility of our study.

- The response rate of $47 \%$ in the work-related problems study could have biased the results, but the patients who participated were of the same age as and with similar diagnoses to those who did not participate.

\section{INTRODUCTION}

Improved diagnosis and treatment, increasing incidence rates and a prolonged life expectancy have steadily increased the number of people living with a cancer diagnosis. ${ }^{1}$ During the next decade, a further rapid increase in the number of new cancer diagnoses in the population can be expected. $^{2}$ 
The most common cancer in Europe is colorectal cancer $(14 \%$ of the total), while other gastrointestinal (GI) cancers such as stomach $(5 \%)$, pancreatic $(3 \%)$, liver $(1.9 \%)$ and oesophageal cancer $(1.4 \%)$ are respectively the fifth, seventh, 16 th and 19 th most common cancers in Europe. ${ }^{3}$

To improve the quality of care for these patients, many healthcare providers have embraced patient-centred care solutions. These organisational solutions often include aspects such as timely access to care, reduced waiting times, personalised information and the coordination of multidisciplinary care. To deliver patientcentred care to patients with GI cancer, the Gastrointestinal Oncology Center Amsterdam (GIOCA) provides a comprehensive one-stop, rapid access diagnostic assessments for patients suspected of having GI cancer. During a single visit, previous diagnostic tests are reevaluated, and additional tests are performed. A multidisciplinary oncology team formulates a diagnosis and forms a treatment plan. Patients have subsequent consultations with several members of a multidisciplinary oncology team for treatment explanation. GIOCA also aims at providing adequate psychosocial oncological care including support on social problems such as work issues after cancer diagnosis.

Almost half of the people diagnosed with cancer are of working age, ${ }^{4}$ and it is expected that the number of cancer patients who are of working age will increase. To be able to work and to be employed are very important. These have a very strong association with cancer survivors' quality of life,$^{5-7}$ give social standing and play a crucial role in many lives. Employment also supplies a much needed income for cancer patients and their families.

Several studies have assessed the employment status of cancer patients, ${ }^{8}$ but the majority of those focused on breast-cancer patients and not on the highly prevalent patients with GI cancer. Furthermore, most work-related research has been carried out on cancer patients with a good prognosis, and problems of patients with other diagnoses such as oesophageal cancer or pancreatic cancer have been insufficiently studied. ${ }^{8}$ Little is known, therefore, about their employment status, how many patients are at risk and what work-related problems play a role at the time of diagnosis.

This information is essential to better support patients with GI cancer with their employment problems. Clinicians could play an important role in detecting patients at risk for work-related and employment problems, ${ }^{9}$ while these problems could already occur at the time of diagnosis. If a clinician suspects work-related problems, referral to occupational specialists could be considered at an early stage during the treatment process. Furthermore, innovative clinical interventions to support cancer patients with work-related issues are available for cancer patients, which are executed from the clinical setting. ${ }^{10} 11$

The aim of this inventory study is to (1) assess the employment status of patients with GI cancer at time of diagnosis; and (2) to examine work-related problems of employed patients with GI cancer at the time of diagnosis.

\section{MATERIALS AND METHODS \\ Patients}

Consecutive patients were recruited from patients referred to the GIOCA between May 2010 and November 2010. GIOCA is a one-stop outpatient clinic for patients with (suspicion of) GI malignancy. The GIOCA nurses arrange for all previously performed diagnostic tests to be reviewed by the radiologist and for additional or missing diagnostic tests to be determined. After these morning visits, a specialised multidisciplinary meeting takes place, in which all involved specialists participate, including oncologists, radiotherapists, surgeons and gastroenterologists. A presumed diagnostic conclusion and a subsequent treatment plan are formed for each patient. In the afternoon, the patient meets the medical specialist and all treating physicians to discuss the diagnosis and treatment plan. Only endoscopic diagnostics are performed before the visit. Treatment starts within 3 weeks after this visit to the one-stop GIOCA clinic.

Eligible patients had to have a primary diagnosis of GI cancer, had to speak Dutch and had to sign informed consent obtained by an oncology nurse. Patients participating in the study assessing work-related problems additionally had to be in paid employment at the time of diagnosis. The Medical Ethics Committee of the Academic Medical Centre Amsterdam approved of the study idea but deemed ethical review unnecessary because this observational study did not involve a medical intervention.

\section{Design}

Consecutive new patients were approached by the oncology nurse at the first visit to the centre. The nurse asked patients current employment status (pensioner, (self)-employed or not employed), asked employed patients if they were interested in a work-related survey and provided them with written information. If patients were willing to participate, they were asked by their nurse at their first visit at the GIOCA outpatients' centre to sign informed consent. They were further asked to fill in a questionnaire on their employment status, workrelated problems, sociodemographic data, fatigue, work ability and burden of disease. If the questionnaire could not be completed at the centre, patients could take it home and return the questionnaire by mail.

The length of recruitment period of half a year and the restriction to one medical centre were chosen because the estimated number of 350 new consecutive patients would be sufficient to provide input for an inventory study.

\section{Measures}

Data from medical files

Information on diagnosis, employment status ((self)employed, pensioner, unemployed, housewife or not 
working, studying, disability pension or early retirement), profession and age was retrieved from the medical files by one of the authors (medical doctor, DB).

\section{Data from survey}

Sociodemographic data included education (lower, high school, college/university), sex and marital status (single/widowed, married/cohabitating, divorced).

\section{Employment status and work-related problems}

Questions on employment included: paid employment (yes/no). If yes: current profession or function, number of years in current occupation, did work make disease complaints worse (yes/no), and current sick leave (yes/ no). If not on sick leave: how many hours per week working. If on sick leave: since when, partial or total sick leave, is the cancer work-related (yes/no), is sick leave caused by current disease complaints (yes/no), contact with occupational physician (yes/no), able and willing to work (yes/no), main barriers for not working, and return to work if those barriers were taken away (yes/ no). If a patient is working and does not experience any problems: what facilitated this?

\section{Work ability, fatigue and burden of disease}

Current work ability was measured with the first three items from the Work Ability Index, ${ }^{12}$ which is a reliable, valid and widely used instrument. Current work ability was assessed by asking the patients to estimate their current work ability compared with their lifetime best $(0=$ cannot work at all to $10=$ best ever $)$. In addition, we asked the cancer patients to rate both their current physical and mental work ability in relation to job demands $(0=$ cannot work at all to $10=$ best ever $)$.

Fatigue was assessed with the Multidimensional Fatigue Inventory (MFI) which is a 20-item self-report instrument with answers ranging from 1 (yes, ie, true) to 5 (no, ie, not true).$^{13}$ It covers the following dimensions: general fatigue (four items), physical fatigue (four items), mental fatigue (four items), reduced motivation (four items) and reduced activity (four items), and has excellent validity and reliability. ${ }^{13}$

Burden of disease was measured with the distress thermometer and problem list. ${ }^{14}$ The distress thermometer is a single-item, self-report measure of distress with an 11-point range from 0 (no distress) to 10 (extreme distress) with good reliability and validity. The problem list consists of practical problems (seven items), family/social problems (three items), emotional problems (nine items), religious/spiritual problems (two items) or physical problems (25 items) in the past week.

\section{Statistical analysis}

All new, consecutive patients in the study period were included. Because the study concerns an inventory study, no statistical power analysis for the determination of study size had to be performed. For the calculation of the subscales of the MFI, a subscale score was calculated if no more than $50 \%$ of the items of that subscale were missing. No other data were imputed.

Descriptive analyses on employment status, age, marital status, education and occupation were performed. Nonparticipation in the survey study was examined on several factors. Differences in age and diagnosis of employed patients who were and were not willing to participate in the work-related problems study were compared with a $t$ test for age and a $\chi^{2}$ test for diagnosis. Differences in age, sex, sick leave (yes/no) by diagnosis and in sex by age and sick leave (yes/no) were analysed with $\chi^{2}$ tests for categorical data, and t tests and ANOVAs for age. To analyse differences in work ability, fatigue, distress and cancer-related problems between employed patient who were on sick leave at the time of diagnosis and those still working, ANOVAs were performed.

Alpha was set at 0.05 unless stated otherwise, and all tests were two-sided. Analyses were conducted with SPSS V.18.

\section{RESULTS}

A total of 387 new consecutive patients were potentially eligible to participate in the study (see figure 1). Of these, 333 patients were included in the study, while 54 patients were excluded because they were diagnosed with benign disease $(n=47)$ or their employment status had not been assessed $(\mathrm{n}=7)$. Of the 333 patients in the study, 179 $(54 \%)$ were retired, 59 were not working $(18 \%)$, and 95 patients $(28 \%)$ were employed at the time of diagnosis. The 95 employed cancer patients were invited to participate in the survey study to assess work-related problems to which $55(58 \%)$ consented, of which $45(82 \%)$ patients completed and returned the questionnaire.

Table 1 shows the age, cancer-related characteristics and employment status at diagnosis of the entire sample of 333 patients. The diagnosis was HPB cancer for $47 \%$ of the patients, while $32 \%$ were diagnosed with

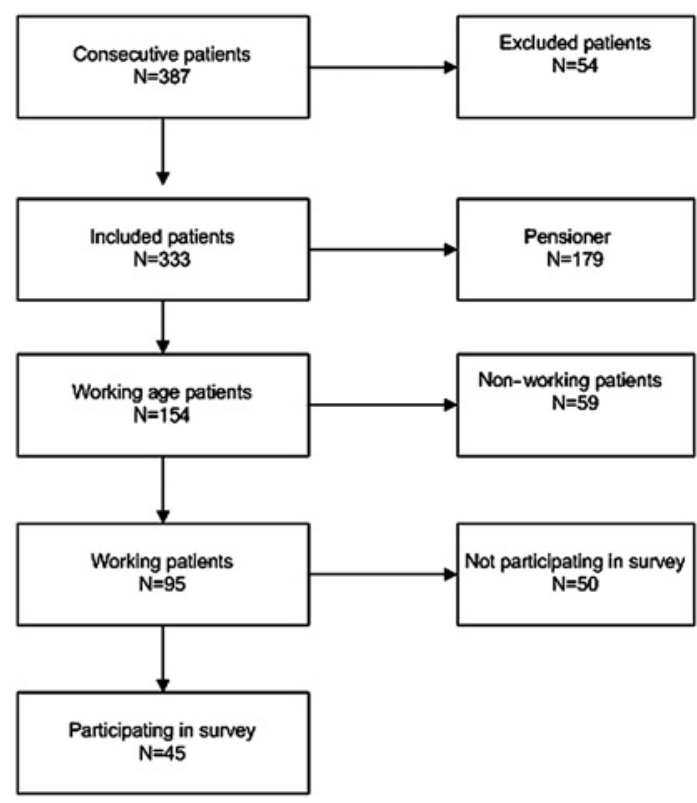

Figure 1 Flow chart of patient inclusion. 
Table 1 Age, cancer-related characteristics and employment status: included sample

\begin{tabular}{lc}
\hline $\mathbf{N}=\mathbf{3 3 3}$ patients & \\
\hline Mean age (range, SD) & $66(32-89,11)$ \\
& $\mathrm{n}(\%)$ \\
Diagnosis & $106(32)$ \\
Oesophageal or stomach cancer & $70(21)$ \\
Colorectal cancer & $155(47)$ \\
Hepatic, pancreatic or biliary cancer & $2(1)$ \\
Other oncology & \\
Employment status & $179(54)$ \\
Pensioner (>65 years) & $83(25)$ \\
Employed & $12(4)$ \\
Self-employed & $2(1)$ \\
Unemployed & $34(10)$ \\
Housewife or not working & $2(1)$ \\
Student & $5(1)$ \\
Disability pension & $16(5)$ \\
Early retirement (<65 years) &
\end{tabular}

oesophageal or stomach cancer and $21 \%$ with colorectal cancer. Most patients were pensioners (54\%), while $29 \%$ were (self)-employed and $10 \%$ housewives or not working.

Of the 95 working patients, 45 participated in the study assessing work-related problems. The main reason for not participating was the recent upsetting news of cancer diagnosis. No differences were found in age (55.7 vs 53.3 years, $\mathrm{p}=0.24)$ or diagnosis $(\mathrm{p}=0.37)$ between the group of 45 employed patients who participated and the 50 patients who did not. The mean age of the 45 participating employed patients was 56 years (range $35-78$ years), and 35 patients $(78 \%)$ were male (see table 2). Most patients (87\%) were married, and $44 \%$ had a college or university degree. The most prevalent diagnosis was oesophageal or stomach cancer (49\%), while the other patients had been diagnosed with either colorectal $(18 \%)$ or HPB cancer $(33 \%)$.

\begin{tabular}{|c|c|}
\hline \multicolumn{2}{|l|}{$\mathrm{N}=45$ patients } \\
\hline Mean age (range, SD) & $\begin{array}{l}56(35-78,8)^{*} \\
n(\%)\end{array}$ \\
\hline Sex (male) & $35(78)$ \\
\hline \multicolumn{2}{|l|}{ Education } \\
\hline Lower & $14(31)$ \\
\hline High school & $11(24)$ \\
\hline College/university & $20(44)$ \\
\hline \multicolumn{2}{|l|}{ Marital status } \\
\hline Single/widowed/divorced & $6(13)$ \\
\hline Married/cohabiting & $39(87)$ \\
\hline \multicolumn{2}{|l|}{ Diagnosis } \\
\hline Oesophageal or stomach cancer & $22(49)$ \\
\hline Colorectal cancer & $8(18)$ \\
\hline Hepatic, pancreatic or biliary cancer & $15(33)$ \\
\hline
\end{tabular}

Although $60 \%$ of the female patients was diagnosed with HPB cancer and $30 \%$ with oesophageal or stomach cancer versus $26 \%$ and $54 \%$, respectively, of male patients, the differences were not statistically significant $(p=0.13)$. No differences in age between male and female patients $(p=0.32)$ or between diagnoses $(\mathrm{p}=0.34)$ were found. The percentage of patients on sick leave was $46 \%, 25 \%$ and $73 \%$ for patients with oesophageal/stomach cancer, colorectal cancer or HPB cancer, respectively $(p=0.07)$. The percentage of patients on sick leave was not statistically significant different for men $(46 \%)$ or women $(70 \%)(p=0.18)$.

Table 3 lists the work-related characteristics and problems of the employed patients with GI cancer. Patients had worked in their current profession for a mean period of 21 years. Their professions included directors, teachers, managers, bus drivers, bakers,

Table 3 Work-related characteristics and problems at diagnosis

\begin{tabular}{|c|c|}
\hline \multicolumn{2}{|l|}{$\mathrm{N}=45$ patients } \\
\hline $\begin{array}{l}\text { Years (mean) in current } \\
\text { profession (range, SD) }\end{array}$ & 21 years $(0.5-65,14)$ \\
\hline $\begin{array}{l}\text { Complaints worsened } \\
\text { because of work? }\end{array}$ & n (\%) \\
\hline No & $41(98)$ \\
\hline Yes & $1(2)$ \\
\hline \multicolumn{2}{|c|}{ Work influenced cancer occurrence? } \\
\hline No & $19(95)$ \\
\hline Yes & $1(5)$ \\
\hline \multicolumn{2}{|l|}{ Current sick leave? } \\
\hline No & $22(49)$ \\
\hline Yes & $23(51)$ \\
\hline \multicolumn{2}{|c|}{ If yes, is sick leave related to cancer? } \\
\hline No & $2(9)$ \\
\hline Yes & $20(91)$ \\
\hline \multicolumn{2}{|l|}{ Main factor for sick leave? } \\
\hline Fatigue & $4(17)$ \\
\hline Pain & $3(13)$ \\
\hline Stress & $8(35)$ \\
\hline (Waiting for) operation & $6(26)$ \\
\hline Other & $2(8)$ \\
\hline \multicolumn{2}{|l|}{ Would you like to work? } \\
\hline No & 7 (33) \\
\hline Yes & $14(67)$ \\
\hline \multicolumn{2}{|c|}{ Contact with occupational physician on sick leave? } \\
\hline No & $16(70)$ \\
\hline Yes & $7(30)$ \\
\hline \multicolumn{2}{|l|}{ Work-related problems? } \\
\hline Yes & $33(73)$ \\
\hline No & $12(27)$ \\
\hline \multicolumn{2}{|c|}{ If no, what facilitated working without problems? } \\
\hline No health problems & $3(25)$ \\
\hline Employer's support & $2(17)$ \\
\hline Flexible work hours & $2(17)$ \\
\hline Work provides distraction & $1(8)$ \\
\hline Other & $3(25)$ \\
\hline
\end{tabular}


secretaries, artists, cleaners, ICT workers, salesmen, carpenters and project leaders. Twenty-two patients $(49 \%)$ were still at work with a mean of 37 working hours per week (range $10-60 \mathrm{~h}$ ), while 23 patients $(51 \%)$ were on sick leave with a mean sick leave of 0.8 months (range $0-2$ months). The main factors of sick leave were stress $(35 \%)$, (scheduled) operation $(26 \%)$, fatigue $(17 \%)$ and pain $(13 \%)$. Most cancer patients on sick leave $(70 \%)$ did not have any contact with their occupational physician regarding their illness and sick leave, while the majority $(67 \%)$ would like to work. Twelve patients did not experience any workrelated problems, facilitated mainly by support from the employer or flexible work hours.

Table 4 lists the mean values of current work ability, fatigue, distress and cancer-related problems. The mean current work ability was $5.4(0-10)$, and the mean general fatigue score was $11.5(4-20)$. The mean score on the distress thermometer was $4.7(0-10)$. On average, patients reported five physical problems, with fatigue (reported by $40 \%$ of patients), pain (38\%) and eating problems $(38 \%)$ being the most prevalent. Furthermore, patients experienced a mean of two emotional problems and one practical problem. Family problems and religious problems were infrequently encountered.

Employed patients on sick leave at the time of diagnosis reported a lower general work ability, lower physical work ability and lower mental work ability. Those on sick leave also experienced more general fatigue, physical fatigue and mental fatigue in addition to higher levels of restricted activity and restricted motivation. They showed higher levels of distress but no more cancer-related practical, family, emotional, religious or physical problems.

\section{DISCUSSION}

\section{Employment status of patients with GI cancer}

The first aim of our study was to assess the employment status of patients with GI cancer at time of diagnosis. We found that of all 333 new consecutive patients with GI cancer diagnosed in our GIOCA centre, most $(54 \%)$ were retired, while 95 (29\%) were employed. Of these 95 patients, 45 participated in a study of work-related problems. Half of them were on sick leave at the time of diagnosis, although only for a relatively short time of less than a month and mainly due to stress and fatigue. The majority of patients on sick leave had no contact with their occupational physician, but they would like to work. Facilitators to continue working were a supportive employer and flexible working hours. Employed patients on sick leave at time of diagnosis reported a lower work ability, more fatigue and more distress compared with those still working.

The results presented expand our knowledge on the employment status of patients with GI cancer at diagnosis. Showing that a considerable part of the GI patients presented to an oncological centre is employed will stimulate the discussion on the necessity of proving work-related care during the treatment phase. By executing a design of consecutive inclusion, the employment status of all patients with GI cancer has been examined, and not merely of those of working age or those with a good prognosis.

Very few data exist on the employment status of cancer patients at diagnosis. A recent study in Canada on employment status of 2422 lung cancer and colorectal cancer survivors showed that $39 \%$ of patients aged 21-80+ years were working before diagnosis. ${ }^{15}$ However, separate figures for colorectal cancer were not provided, so we cannot compare our finding of $29 \%$ of working

Table 4 Mean value of current work ability, fatigue, distress and work-related problems according to sick-leave status

\begin{tabular}{|c|c|c|c|c|}
\hline $\mathrm{N}=45$ patients & $\begin{array}{l}\text { Sick leave, } \\
N=23 \text { patients }\end{array}$ & $\begin{array}{l}\text { No sick leave, } \\
\mathrm{N}=22 \text { patients }\end{array}$ & p Value & $\begin{array}{l}\text { Total, } \mathrm{N}=45 \\
\text { patients }\end{array}$ \\
\hline \multicolumn{5}{|l|}{ Work ability $(0-10)$} \\
\hline Current work ability ${ }^{\star}$ & $3.7(2.2)$ & $7.1(2.7)$ & $<0.001$ & $5.4(2.9)$ \\
\hline Current physical work ability* & $4.3(2.6)$ & $7.3(3.0)$ & 0.001 & $5.8(3.2)$ \\
\hline Current mental work ability* & $3.6(2.3)$ & $6.9(2.9)$ & $<0.001$ & $5.3(3.1)$ \\
\hline \multicolumn{5}{|l|}{ Fatigue $(4-20)$} \\
\hline General fatigue & $14(4.4)$ & $9(4.1)$ & $<0.001$ & $12(5.2)$ \\
\hline Physical fatigue $†$ & $14(4.7)$ & 8 (3.9) & $<0.001$ & $11(5.4)$ \\
\hline Restricted activity $\dagger$ & $15(4.0)$ & $10(4.1)$ & 0.001 & $13(4.7)$ \\
\hline Restricted motivation $†$ & $13(4.2)$ & $9(3.8)$ & $<0.001$ & $11(4.6)$ \\
\hline Mental fatigue $\dagger$ & $13(5.1)$ & $9(4.9)$ & 0.005 & $11(5.4)$ \\
\hline \multicolumn{5}{|l|}{ Distress } \\
\hline General distress scale $(0-10)$ & $3.7(2.5)$ & $5.6(2.2)$ & 0.023 & $4.7(2.5)$ \\
\hline \multicolumn{5}{|l|}{ Problems } \\
\hline Practical problems (0-7) & $0.9(1.1)$ & $0.7(1.1)$ & 0.67 & $0.8(1.1)$ \\
\hline Family problems $(0-3)$ & $0.1(0.3)$ & $0.1(0.4)$ & 0.97 & $0.1(0.4)$ \\
\hline Emotional problems $(0-9)$ & $2.5(1.6)$ & $1.9(2.1)$ & 0.35 & $2.2(1.9)$ \\
\hline Religious problems (0-2) & $0.0(0.0)$ & $0.2(0.5)$ & 0.17 & $0.1(0.4)$ \\
\hline Physical problems (0-25) & $5.8(3.9)$ & $3.8(2.9)$ & 0.08 & $4.9(3.6)$ \\
\hline
\end{tabular}


patients in the entire sample of patients with GI cancer with those in the Canadian study. In an earlier trial on oesophageal cancer patients, we found a similar working rate with 22/88 (25\%) patients employed at diagnosis compared with $26 \%$ in this study. ${ }^{16}$ A recent trial on Dutch breast-cancer patients with a mean age of 55 years showed a higher employment rate at diagnosis of $49 \%{ }^{17}$ However, the patients in our study were much older with a mean age of 66 years.

\section{Work-related problems of patients with GI cancer}

The second aim of the study was to examine work-related problems of employed patients with GI cancer at the time of diagnosis. In our study, half of the employed cancer patients $(51 \%)$ were on sick leave at the time of diagnosis, mostly because of distress. Interestingly, few of these $(30 \%)$ had consulted their occupational physician, although many would have liked to work. Earlier research has shown that the quality of the occupational physician's performance and the continuity of care are related to return to work of cancer patients. ${ }^{18}$ Furthermore, a study on 797 UK occupational physicians showed that referral of cancer patients may take place too late to be effective in securing a return to work. ${ }^{19}$ Therefore, it is very important that an independent occupational physician or expert is a member of the multidisciplinary oncology team in the hospital. Alternatively, cancer patients with work-related problems should be referred very early in the treatment process to an occupational expert by the treating specialist or attending nurse in the hospital.

In the present study, the mean current work ability score was 5.4, which is higher than the score of 4.6 we found for cancer survivors 6 months after diagnosis but lower that the score of 6.7 we found in the same group at 18 months after diagnosis. ${ }^{9}$ Earlier studies have shown that work ability can deteriorate due to cancer,${ }^{20-22}$ but our results show that work ability can already deteriorate before treatment. A one-point decrease in perceived work ability, on a 10-point scale, has been shown to be associated with an increased risk of long-term sickness absence of $15 \%$ and an increased risk of early retirement from the labour market of $33 \% .{ }^{23}$ Therefore, it is very important to sustain work ability in cancer patients.

Compared with colorectal cancer patients receiving chemotherapy in an earlier Austrian study, fatigue levels of all MFI subscales were lower in our cohort of working patients at diagnosis. ${ }^{24}$ General fatigue in these patients receiving their first cycle of chemotherapy was higher with 12.5 compared with 11.5 in our study. However, the general fatigue score of matched healthy controls in the Austrian study was 7.8, and so our patients showed elevated fatigue levels, while the Austrian patients were slightly older (60 years compared with 56 years in our sample). The mean score on the distress thermometer of our study patients was 4.7 , which is comparable with scores of lung-cancer patients at baseline (4.6-5.2) but higher than levels of distress in breast-cancer patients $(3.5-3.9) .{ }^{25}$ However, these patients were older
(62 years) than our patients (56 years), and $50 \%$ of them were retired, which might have induced lower distress levels. Because cancer patients scoring $\geq 4$ on the distress thermometer should be offered additional psychosocial support and referral to appropriate services, many patients in our study should be offered this possibility. It is possible that patients from our clinic were more distressed because of the timing of the measurement. The distress thermometer was assessed in the morning, while the diagnosis was given in the afternoon. Hence, patients are likely to show high levels of distress.

Most importantly, our study on work-related problems of employed patients with GI cancer at time of diagnosis shows in particular opportunities to aim to solve the workrelated problems encountered by the patients at a very early stage. Employment outcomes can be improved with innovations in treatment and with clinical and supportive services aimed at better management of symptoms, rehabilitation and accommodation of disabilities. ${ }^{26}$ If patients keep participating in work life as much as possible, the chances of work retention increase significantly. Therefore, interventions should be developed to enable cancer survivors to return to work or succeed in other appropriate employment as early as possible. Clinicians could play an important role in detecting those patients at risk because our study has shown that the indication of patients with a possible return to work problems can be assessed very early in the treatment process when they indicate they have work-related problems. Recently, several interventions aimed at supporting patients with their work-related problems have been developed. For employed cancer patients, we developed a work-directed intervention in which a psycho-oncology nurse supports cancer patients in their return to work from the hospital setting. She provides advice and guidance on managing symptoms at work, on communication with employer, on communication between the medical specialist and occupational physician, on legal issues and information on work ability during and after treatment. The employer is engaged as well to make work participation and re-entry possible. ${ }^{11}$ In the UK, an intervention was developed and will be tested for colorectal cancer patients in which they were provided with an educational leaflet and a face-to-face return-to-work consultation with an oncology nurse. This was tailored according to work type (manual/non-manual). ${ }^{27}$

GIOCA aims at providing high-quality diagnosis and treatment for patients with GI cancer. Moreover, it strives for adequate social oncological care including support on work issues after cancer diagnosis. In future, workfocused interventions before, during and after diagnosis could be added to the oncological care and prove to be very powerful for colorectal cancer patients.

\section{Strengths and limitations}

The goal of our study was to assess the employment status of a complete cohort patients with GI cancer at the time of diagnosis. We succeeded in including all consecutive new patients who were diagnosed in our centre. 
Our study has several limitations. The response rate to our questionnaire on work-related problems was $47 \%$. This is comparable with $49 \%$, the response rate of the survey on employment status among Canadian survivors of lung and colorectal cancer, ${ }^{15}$ but is a relatively low response rate compared with the $80 \%$ response rate of Dutch cancer survivors on experienced work changes after diagnosis. ${ }^{7}$ The response rate could have biased the results, but the patients who participated were of the same age as and with similar diagnoses to those who did not participate. The responders do appear to be relatively highly educated, which could have underestimated the work problems of those patients with a lower education. They more often have physically demanding jobs with fewer possibilities for work accommodations, which imply more work-related problems.

At the start of the study, we included 333 patients, which is a considerably large clinical sample. However, compared with large (registration-based) studies on cancer patients, the number of patients in our final work-related problems analyses, 45, was moderate. However, these 45 patients gave us unprecedented new knowledge on the work-related problems cancer patients experience at diagnosis. A larger number of patients in our final sample would nevertheless have helped in providing more in-depth results in addition to descriptive crude overall findings. In addition, a larger sample size would have given statistical power to elaborate on the differences between subgroups of patients; for instance, gender-specific issues could have been explored.

Our cancer centre, GIOCA, is an academic centre specialising in the diagnosis and treatment of oesophageal cancer and pancreatic cancer, and it serves as a secondary and tertiary referral centre. It provides second opinions for more complicated cases of colorectal cancers. Therefore, most patients in our study had a diagnosis of oesophageal or pancreatic cancer, which are not the most prevalent GI cancers. This might affect the generalisibility of the results to the entire population of GI patients because the impact of oesophageal or pancreatic cancer diagnosis on employment could be different from that of colorectal cancer. Our patient population could be biased towards fewer palliative diagnoses as well, because the referring centres may refer fewer patients with incurable cancer.

Finally, of all patients in the working age, $62 \%$ were employed. This is slightly lower than the $65 \%$ employment rate in the European Union but considerably lower than the $77 \%$ Dutch employment rate. ${ }^{28}$ This difference is most probably caused by the higher mean age of the study groups compared with the general population. For instance, younger women are less often housewives than older women.

\section{Conclusion}

Physicians can help cancer patients with their return to work process very early in the treatment process. They can enquire about the patients' employment status, evaluate work-related problems, and guide them in the level and type of work participation. During the diagnosis stage, information and support on work-related issues should be available. Thereafter, during and after treatment, offering an appropriate work-directed intervention or referral is essential to high-quality oncological care. A substantial proportion of their patients could thus be helped in improving their quality of life.

\section{Author affiliations}

${ }^{1}$ Coronel Institute of Occupational Health (Outpatient Clinic People and Work), Academic Medical Center, University of Amsterdam, Amsterdam, The Netherlands

${ }^{2}$ Department of Gastroenterology and Hepatology, Academic Medical Center, University of Amsterdam, Amsterdam, The Netherlands

${ }^{3}$ Gastrointestinal Oncology Center Amsterdam (GIOCA), Academic Medical Center, University of Amsterdam, Amsterdam, The Netherlands

${ }^{4}$ Department of Surgery, Academic Medical Center, University of Amsterdam, Amsterdam, The Netherlands

Acknowledgements We would like to thank all patients for their contribution to this study, and J Ruijs for his contribution to the data collection for this study.

Funding This research received no specific grant from any funding agency in the public, commercial or not-for-profit sectors.

\section{Competing interests None.}

\section{Patient consent Obtained.}

Ethics approval Ethics approval was provided by The Medical Ethics Committee of the Academic Medical Centre, Amsterdam.

Contributors AGEMdB: data analysis, writing this article. DJB: study design, data collection, data analysis, reviewed and critiqued this article. KMAJT: study design, reviewed and critiqued this article. AS: study design, data collection, reviewed and critiqued this article. JHGK: study design, reviewed and critiqued this article. MHWF-D: study design, reviewed and critiqued this article.

Provenance and peer review Not commissioned; externally peer reviewed.

Data sharing statement No further data available.

\section{REFERENCES}

1. Fosså SD, Vassilopoulou-Sellin R, Dahl AA. Long term physical sequelae after adult-onset cancer. J Cancer Surviv 2008;2:3-11.

2. Jansen $\mathrm{L}$, Koch $\mathrm{L}$, Brenner $\mathrm{H}$, et al. Quality of life among long-term (5years) colorectal cancer survivors-Systematic review. Eur J Cancer 2010;46:2879-88.

3. Ferlay J, Parkin DM, Steliarova-Foucher E. Estimates of cancer incidence and mortality in Europe in 2008. Eur J Cancer 2010;46:765-81.

4. Short P, Vasey JJ, Tuncelli K. Employment pathways in a large cohort of adult cancer survivors. Cancer 2005;103:1292-301.

5. Fleer J, Hoekstra HJ, Sleijfer DT, et al. Quality of life of testicular cancer survivors and the relationship with sociodemographics, cancer-related variables, and life events. Support Care Cancer 2006; 14:251-9.

6. Mellon S, Northouse LL, Weiss LK. A population-based study of the quality of life of cancer survivors and their family caregivers. Cancer Nurs 2006;29:120-31.

7. Mols F, Thong MS, Vreugdenhil G, et al. Long-term cancer survivors experience work changes after diagnosis: results of a populationbased study. Psychooncology 2009;18:1252-60.

8. de Boer AG, Taskila T, Ojajärvi $\mathrm{A}$, et al. Cancer survivors and unemployment: a meta-analysis and meta-regression. JAMA 2009;301:753-62.

9. de Boer AG, Verbeek JH, Spelten ER, et al. Work ability and returnto-work in cancer patients. Br J Cancer 2008;22:1342-7.

10. Nieuwenhuijsen K, Bos-Ransdorp B, Uitterhoeve LL, et al. Enhanced provider communication and patient education regarding return to work in cancer survivors following curative treatment: a pilot study. $J$ Occup Rehabil 2006;16:647-57.

11. Tamminga SJ, de Boer AG, Verbeek JH, et al. Enhancing return-towork in cancer patients, development of an intervention and design of a randomised controlled trial. BMC Cancer 2010;10:345-54. 
12. Tuomi K, Ilmarinen J, Jahkola A. Work Ability Index, 2nd revised ed. In: Helsinki, Finnish Institute of Occupational Health, Helsinki, 1998.

13. Smets E, Garssen G, Bonke B, et al. The Multidimensional Fatigue Inventory (MFI), psychometric qualities of an instrument to assess fatigue. J Psychometric Res 1995;39:315-25.

14. Tuinman MA, Gazendam-Donofrio SM, Hoekstra-Weebers JE. Screening and referral for psychosocial distress in oncologic practice: use of the Distress Thermometer. Cancer 2008;113:870-8.

15. Earle CC, Chretien Y, Morris C, et al. Employment among survivors of lung cancer and colorectal cancer. J Clin Oncol 2010;28:1700-5.

16. de Boer AG, van Lanschot JJ, van Sandick JW, et al. Quality of life after transhiatal compared with extended transthoracic resection for adenocarcinoma of the esophagus. J Clin Oncol 2004;22:4202-8.

17. de Kok M, van der Weijden T, Voogd AC, et al. Implementation of a short-stay programme after breast cancer surgery. Br J Surg 2010;97:189-94.

18. Verbeek J, Spelten E, Kammeijer M, et al. Return to work of cancer survivors: a prospective cohort study into the quality of rehabilitation by occupational physicians. Occup Environ Med 2003;60:352-7.

19. Amir Z, Wynn P, Whitaker S, et al. Cancer survivorship and return to work: UK occupational physician experience. Occup Med (Lond) 2009;59:390-6.

20. Kennedy F, Haslam C, Munir F, et al. Returning to work following cancer: a qualitative exploratory study into the experience of returning to work following cancer. Eur J Cancer Care 2007;16:17-25.
21. Taskila $\mathrm{T}$, Martikainen $\mathrm{R}$, Hietanen $\mathrm{P}$, et al. Comparative study of work ability between cancer survivors and their referents. Eur $J$ Cancer 2007;43:914-20.

22. Gudbergsson SB, Fossa SD, Borgeraas E, et al. A comparative study of living conditions in cancer patients who have returned to work after curative treatment. Support Care Cancer 2003;14:1020-9.

23. Sell L, Bültmann $U$, Rugulies $R$, et al. Predicting long-term sickness absence and early retirement pension from self-reported work ability. Int Arch Occup Environ Health 2009;82:1133-8.

24. Holzner B, Kemmler G, Greil R, et al. The impact of hemoglobin levels on fatique and quality of life in cancer patients. Ann Oncol 2002;13:965-73.

25. Carlson LE, Groff SL, Maciejewski O, et al. Screening for distress in lung and breast cancer outpatients: a randomized controlled trial. $J$ Clin Oncol 2010;28:4884-91.

26. Steiner JF, Cavender TA, Main DS, et al. Assessing the impact of cancer on work outcomes. Cancer 2004;101:1703-11.

27. Bains M, Munir F, Yarker J, et al. Return-to-Work Guidance and Support for Colorectal Cancer Patients: A Feasibility Study. Cancer Nurs. Published Online First: 2 March 2011. doi:10.1097/NCC.0b013e31820a4c68.

28. http://epp.eurostat.ec.europa.eu/portal/page/portal/ employment_unemployment_lfs/data/main_tables (accessed 5 Apr 2011). 